\title{
Autologous Hematopoietic Stem Cell Transplantation (AHSCT): An Evolving Treatment Avenue in Multiple Sclerosis
}

\author{
Reihane Mohammadi' \\ Alisam Aryan² \\ Mir Davood Omrani (iD) \\ Sayyed Mohammad Hossein \\ Ghaderian (iD) \\ Zahra Fazeli (iD ' \\ 'Department of Medical Genetics, \\ Faculty of Medicine, Shahid Beheshti \\ University of Medical Sciences, Tehran, \\ Iran; ${ }^{2}$ Faculty of Medicine, Shahid \\ Beheshti University of Medical Sciences, \\ Tehran, Iran
}

This article was published in the following Dove Press journal: Biologics: Targets and Therapy

\begin{abstract}
Autologous hematopoietic stem cell transplantation (AHSCT) is considered as the novel approach to improve multiple sclerosis (MS) patients with disease-modifying therapies (DMTs)-resistance. The results obtained from different studies indicate that AHSCT increases the life quality of MS patients. Several factors are known to be influenced on the successful rate of AHSCT in patients with MS. The individuals aged $<40$ years with a short duration of MS disease have been demonstrated to show a better response to AHSCT administration. Furthermore, this treatment approach was more effective in relapsing remitting MS (RRMS) patients than progressive MS (PMS). Different clinical trials revealed that AHSCT with a low density conditioning regimen could be suggested as a suitable candidate approach in the management of MS. Several molecular and cellular mechanisms are known to be involved in the resetting of the immune system following the AHSCT infusion in MS patients. These mechanisms play a role in the depletion of auto-reactive lymphocytes and immune system renewal. In the present review, we discuss different clinical and molecular aspects of AHSCT application in the alleviation of MS symptoms.
\end{abstract}

Keywords: autologous hematopoietic stem cells, transplantation, multiple sclerosis, molecular mechanisms, resetting immune system

\section{Introduction}

Multiple sclerosis (MS) is known as a chronic, immune-mediated, neurodegenerative disease with the malfunctioning immune system. The degeneration of the myelin surrounding axons in the central nervous system (CNS) is associated with life-long disability and devastating the quality-of-life in the patients affected by MS. The affected individuals with MS presented with a broad spectrum of the symptoms, including fatigue, muscle incoordination, mobility limitations, and cognitive and ocular impairments. ${ }^{1,2}$ More than 2 million individuals, especially young adults, have been estimated to be affected by this disorder worldwide. However, the prevalence of this disorder varies in different populations. ${ }^{2,3}$ The development of the immune and nervous systems is distinctive between females and males, leading to more prevalence of this disease in women than men. ${ }^{4}$ Although MS is usually found in females, with an earlier onset than males, the disease progressed more slowly in the affected women as compared with the males affected by MS. ${ }^{5}$

The abnormal activation of CD4+ and CD8+ T-cell and the induction of inflammatory responses in the CNS have been known as the pathophysiology
Correspondence: Zahra Fazeli Department of Medical Genetics, Faculty of Medicine, Shahid Beheshti University of Medical Sciences, Tehran, Iran

Email Z.Fazeli@sbmu.ac.ir

Biologics: Targets and Therapy 2021:15 53-59 
mechanism of MS. Furthermore, B cell dysfunction was effective in the MS etiology through overexpression of cytokines including IL-17 and IFN- $\gamma$. Several diseasemodifying therapies (DMTs) are available to manage MS disease. They play an immunosuppressive or immunomodulatory role. Some of them function through the reconstruction of the immune system. The results obtained from different studies indicate that some patients may show no improvement in the symptoms or present with side-effects after taking DMTs. Furthermore, the cost of these drugs was also high. ${ }^{6-9}$

The immune reconstitution (IR) therapies were also suggested to reset the immune system. The results obtained from different studies indicated that the administration of these therapy approaches was associated with long-term remission. ${ }^{10,11}$ Autologous hematopoietic stem cell transplantation (AHSCT) after immunoablation was considered as the suitable IR therapy method in the patients affected by MS. ${ }^{12-14}$

The American Society for Blood and Marrow Transplantation (ASBMT), the National Multiple Sclerosis Society (NMSS), and the European Group for Blood and Marrow Transplantation (EBMT) Autoimmune Disease Working Party (ADWP) have recently published guidelines about AHSCT administration for MS patients. This treatment approach has been selected as a suggested option for active relapsing remitting MS (RRMS) patients with failing in the response to DMTs, while the first line of treatment for aggressive RRMS was AHSCT. ${ }^{15-18}$ DMTsresistant was an indication to use AHSCT in the treatment of MS patients. ${ }^{19-22}$ In the 1990s, AHSCT was administered to the patients with MS for the first time. ${ }^{23,24}$ The registration of more than 1,000 AHSCT infusions has been performed in the EBMT Registry. This database provided some evidence about the administration of AHSCT for different forms of MS. ${ }^{15}$

\section{The Efficiency of AHSCT in MS Therapy}

Zhukovsky et $\mathrm{al}^{25}$ performed an observational study to evaluate the efficiency of AHSCT vs. A lemtuzumab (ALZ) in the management and treatment of RRMS. Their results showed that AHSCT and ALZ had the potential for improvement and stability of disease activity. However, AHSCT plays a more effective role than ALZ in MS patients. Boffa et al also obtained similar results. They found that the relapse rate diminished in the AHSCT- treated patients as compared with the patients with the experience of ALZ administration. ${ }^{26}$

The evaluation of randomized MS patients showed that AHSCT decreased the Expanded Disability Status Scale (EDSS), while DMT increased these scores in the patients. However, increased EDSS has been observed in some patients. Therefore, AHSCT possibly decreased the rate of disability progression but this approach can not completely cease the neurodegeneration in the patients with MS severe form. ${ }^{27-30}$

The administration of DMTs have been revealed to be associated with several adverse events (AEs) including skin necrosis (IFN $\beta / G L A T)$, headache, nausea, progressive multifocal leukoencephalopathy (Natalizumab), pregnancy problems, bradycardia, hypotension, and lymphopenia (Fingolimod). ${ }^{31-36}$ In the recent years, the improvement of AHSCT procedure led to a decrease in the rate of treatment-related mortality (TRM) from $7.3 \%$ to less than $0.5 \%{ }^{29,37}$ Recovery of the disease over 10 years has been also observed in $50 \%$ of the patients treated with AHSCs. ${ }^{38}$

The EBMT has reported that AHSCT improves the disease conditions in more than $90 \%$ of MS patients. ${ }^{15}$ The advantages and disadvantages of this transplantation were investigated in different trials. ${ }^{23,27,28,30,39}$ The results obtained from a Phase II, randomized trial showed that AHSCT significantly decreased the formation of new T2 lesions in RRMS patients as compared with the patients treated with mitoxantrone (MTX). However, no important effect on the disability progression was found. ${ }^{40}$

In many studies, the patients were followed for less than 5 years. ${ }^{30,39,41,42}$ Several studies were performed to evaluate AHSCT efficiency in MS patients for longer periods. ${ }^{12,43,44}$ The patients with no new disease symptoms during 3 years post-AHSCT have been revealed to have better improvement in the response to the treatment. ${ }^{39}$ The results obtained from different studies indicated that AHSCT decreased the establishment of new T2 in more than $70 \%$ of patients affected by MS. This stability remained in the patients for at least 5 years after the administration of hematopoietic stem cells. ${ }^{14,39,45}$ The brain atrophy and the volume of $\mathrm{T} 2$ lesion also decreased in the MS patients following AHSCT. ${ }^{30,42,45}$ Long-term follow-up indicated that the rate of brain atrophy could even reach the rate of normal aging in the patients after AHSCT. ${ }^{12}$ The results of a meta-analysis performed by Sormani et $\mathrm{a}^{37}$ have shown that no evidence of disease activity (NEDA) was observed in more than 
$80 \%$ of MS patients at 2 years after AHSCT. However, the evaluation of NEDA in some long-term studies indicated that disease-free survival could be maintained even for more than 10 years, while the administration of DMTs was associated with less efficiency (less than 30\% NEDA) for almost 5 years in MS patients. ${ }^{46-49}$

\section{AHSCT and Different Forms of MS}

A significant difference was observed between progressive MS (PMS) and RRMS in the response to AHSCT. The studies indicated that AHSCT had a transient effect and the disease symptoms returned over time in the patients affected by PMS. ${ }^{29,43}$ RRMS patients showed the durable alleviation of the symptoms and complications. ${ }^{44}$ The results obtained from some studies revealed that AHSCT had the potential to improve disability in RRMS patients and this remission was maintained for at least 5 years. ${ }^{41,44}$ The comparison of the results obtained from different trials showed that AHSCT had more efficiency in RRMS patients with the lower baseline EDSS than these patients with high EDSS scores. ${ }^{41,50}$

\section{Factors Influencing the Success of AHSCT}

The neurological function assessment indicated that improvement of neurological disability was maintained for at least 2 years after AHSCT. However, the observation of neurological improvement was dependent to the life quality in MS patients. ${ }^{50}$ It has been revealed that the age of patients (less than 40 years), the severity of disability and disease duration (less than 10 years) play an important role in the success of AHSCT in the treatment of MS patients. ${ }^{15,51}$ Furthermore, the efficiency of AHSCT was observed to be higher in the patients with $\mathrm{Gd}+$ lesions at baseline than other MS patients. This factor may provide the suitable conditions to infiltrate the hematopoietic stem cells into the central nervous system (CNS). ${ }^{39}$

Muraro et $\mathrm{al}^{29}$ reported the results obtained from a multicenter cohort study with 281 patients affected by MS. They found that younger patients with RRMS and shorter history of immunotherapy showed the more suitable response to AHSCT. The administration of AHSCT into the patients with lower disability had the better efficiency in 5years follow-up of MS patients. Furthermore, the survey of trial data indicated that the amount of inflammation was effective in the success rate of AHSCT. It was less likely that new gadoliniumenhancing lesions were established in the patients with active inflammation at baseline following AHSCT. These patients showed the better response to this treatment approach. $^{39}$

Different studies indicated that the success of AHSCT in treatment of MS patients was dependent to the intensity of conditioning regimens administrated before AHSCT. The high density of these regimens was associated with the higher mortality rate in the transplanted patients. The administration of low density regimens of immunoablation has been shown to have more suitable efficiency in the treatment of MS patients. ${ }^{13,52}$ Shevchenko et $\mathrm{al}^{53}$ investigated the efficiency and safety of AHSCT along with reduced intensity BEAM-like conditioning regimen in the patients with different forms of MS including RRMS, secondary progressive MS (SPMS), primary progressive MS (PPMS), and progressive relapsing MS (RPMS). They evaluated the disease status in the patients for more than 3 years. Their results showed the stability of EDSS scale without disease progression in almost $50 \%$ of patients after administration of AHSCT + reduced intensity conditioning regimen. Mancardi et al also obtained similar results in Italian patients. They found that the administration of AHSCT with BEAM/ATG (an intermediate intensity conditioning regimen) was associated with the stability of disease course during 4 years in MS patients. $^{28}$

\section{AHSCT Procedure}

AHSCT for MS treatment was performed in some different steps. At first, hematopoietic stem cells (HSCs) and hematopoietic progenitor cells (HPCs) were mobilized. To do it, the stimulating agents including cyclophosphamide (Cyc) and granulocyte colony-stimulating factor (G-CSF) were used to proliferated HSCs/HPCs and deplete the lymphocytes. Then, these cells were collected. In the next step, the administration of the conditioning regimen and the infusion of HSCs/HPCs were done. After that, the post-transplantation care needs to support the patients from possible complications. The clinical conditions of the patients were also evaluated in the pre-transplantation and the function of different systems of the body was checked. Prior to the transplantation, no symptoms of different infections should be in MS patients. ${ }^{54}$

In the conditioning regimen, the chemotherapy agents were used to remove the immune system. This process enhanced the AHSCT efficiency in the treatment of MS patients. $^{54}$ Immunosuppression before AHSCT removed the auto-reactive lymphocytes. The depletion of 
lymphocytes has been demonstrated to improve the recovery rate and diminish the complications associated with AHSCT. $^{55}$

Following ablation of immune cells, the hematolymphopoietic system restoration was done by infusion of autologous hematopoietic stem cells (AHSCs). Successful results have been obtained from the application of this method in MS patients. ${ }^{56,57}$ RRMS was considered as the best candidate for immunosuppressive therapy with AHSCT. The improved EDSS has been reported in RRMS patients following the administration of immunosuppressive drugs and AHSCT. $^{45}$ The mortality rate was observed to decrease into less than 5\% in the RRMS after treatment with immunosuppressive drugs and AHSCT. ${ }^{12,45}$ Furthermore, the relapse-free survival was reported to increase into more than $80 \%$ in MS patients treated with AHSCT and conditioning regimen. ${ }^{39,41}$

The success of this treatment approach was not observed in the individuals with SPMS. These patients experienced progressive neurodegeneration. The progression of severe disability in these individuals is possibly associated with decreasing the AHSCT efficiency in the alleviation of MS symptoms. ${ }^{58}$

\section{Molecular and Cellular Mechanisms of AHSCT}

AHSCT has been demonstrated to be involved in MS remission through several immune mechanisms. Different studies indicated that these cells were effective in lymphocytes elimination, lymphopenic state induction, tolerant immune system establishment, and functional renewal of the TCR repertoire. ${ }^{59-62} \mathrm{MS}$ patients with higher peripheral blood CD4+/CD8+ T-cells before treatment had been revealed to show the better response to the administration of the conditioning regimen with AHSCT. The expression profiling indicated that the $\mathrm{CD}+8 \mathrm{~T}$-cells population profile of MS patients showed the similarity in expression data with healthy individuals at 2 years post-AHSCT. Furthermore, the obtained results demonstrated that AHSCT modulated the expression level of 27 different genes with role in T-cell activation. $^{63}$ The number of PD-1 expressing T-cells also increased following AHSCT in the patients with MS. PD-1 expressing T-cells was effective in the regulation of lymphocyte hemostasis. PD-1 functions as a negative regulator in proliferation and survival of T-cells. This immune mechanism possibly established immune self-tolerance and limited auto-reactivity response. ${ }^{61,64}$ The enhanced expression of PD-1 has been observed to be important in the clinical outcomes obtained from MS patients following AHSCT (Table 1). ${ }^{65}$ Th1/Th17.1 effector cells ratio was also enhanced after the administration of AHSCT. This reconstitution of T-cell subsets could be considered as a substantial mechanism to improve clinical symptoms in the MS patients after AHSCT. ${ }^{61}$

Molecular analysis revealed that AHSCT modulated the immune system in MS patients through the regulation of miRNA expression. Different studies indicated that miR-142-3p and miR-16 expression enhanced in MS patients. AHSCT has been known to decrease the expression of miR-142-3p and miR-16 in the subjects affected by MS. The diminished expression of these miRNAs was associated with the up-regulation of FOXO1 and FOXP3 expression, inducing $\mathrm{T}_{\text {reg }}$ activity. The decreased expression of miR-16 was also associated with the increased expression of PDCD1, suppressing the inflammation (Table 1). These observations suggested that the epigenetic changes through AHSCT play an immune-regulatory role in MS patients. ${ }^{65-67}$

The evaluation of the intrinsic apoptosis pathway showed that there was the downregulation of BAK and BAX expression as well as the upregulation of BCL2 in MS patients. The results obtained from RNA and protein analysis showed that AHSCT restored the expression of apoptotic genes to the normal level after at least 2 years. ${ }^{68-70}$ Furthermore, the downregulation of extrinsic

Table I The Effect of AHSCT on the Molecular Mechanisms Involved in MS Pathogenesis

\begin{tabular}{|c|c|c|c|}
\hline Genes & $\begin{array}{l}\text { The } \\
\text { Expression at } \\
\text { Post-AHSCT }\end{array}$ & Mechanism & References \\
\hline PD-I & Up-regulation & $\begin{array}{l}\text { The regulation of } \\
\text { lymphocyte } \\
\text { hemostasis }\end{array}$ & [65] \\
\hline FOXOI & \multirow[t]{2}{*}{ Up-regulation } & \multirow{2}{*}{$\begin{array}{l}\text { The induction of } T_{\text {reg }} \\
\text { activity }\end{array}$} & \multirow[t]{2}{*}{ [65-67] } \\
\hline FOXP3 & & & \\
\hline PDCDI & Up-regulation & $\begin{array}{l}\text { The suppression of } \\
\text { inflammation }\end{array}$ & [65-67] \\
\hline BAK & Up-regulation & \multirow{5}{*}{$\begin{array}{l}\text { The suppression of } \\
\text { auto-reactive } \\
\text { lymphocytes }\end{array}$} & \multirow[t]{5}{*}{ [68-70] } \\
\hline BAX & Up-regulation & & \\
\hline $\mathrm{BCl} 2$ & Down-regulation & & \\
\hline FAS & Up-regulation & & \\
\hline FASL & Up-regulation & & \\
\hline
\end{tabular}


apoptosis pathway genes was observed in the untreated MS patients. The expression of FAS and FASL increased following the administration of conditioning regimen in MS patients (Table 1). These findings suggested that the activation of this pathway plays an important role in autoreactive lymphocytes depletion. ${ }^{70}$

\section{AHSCT and Resetting the Immune System}

AHSCT has been suggested to reset the immune system in MS patients through different mechanisms. In the pretransplantation, the pathogenic T-cells were removed and the autoreactive T-cells turned into the tolerant phenotype. The immunoregulatory network was restored to the normal level in the post-transplantation. ${ }^{71}$ Harris et al sequenced $\mathrm{T}$ cell repertoires in peripheral blood and cerebrospinal fluid (CSF) of MS patients. They found that pre-exciting $\mathrm{T}$ cell clones were replaced with new clones in RRMS patients following AHSCT administration. This mechanism removed the pathogenic T cells. ${ }^{72}$

AHSCT has been revealed to establish the balance between pro-inflammatory and regulatory immune cells. This function suppressed the inflammation in the CNS of MS patients. A T-cell subset known as $\mathrm{CD}^{+}$MAITs has also been reported to be depleted in MS patients at postAHSCT. These cells had the ability to produce the proinflammatory cytokines including IL-17, TNF- $\alpha$, and IFN- $\gamma$. Therefore, depletion of these cells at post-transplantation was suggested to have an important role in the downward trend of inflammation in the MS patients. ${ }^{73}$

\section{Conclusion and Future Perspectives}

The results obtained from the clinical trials indicated that the accuracy in the selection criteria of MS patients established suitable conditions for success in AHSCT. The molecular analysis has revealed that AHSCT recovered the expression profile into the healthy state. Different studies showed the apoptotic pathways and different cytokines involved in the pathogenesis of MS. The evaluation of these molecules at post-transplantation could provide better sight about the efficiency of AHSCT with conditioning regimen in the management of MS disease symptoms.

\section{Disclosure}

The authors report no conflicts of interest in this work.

\section{References}

1. Calabresi PA. Diagnosis and management of multiple sclerosis. Am Fam Physician. 2004;70(10):1935-1944.

2. Doshi A, Chataway J. Multiple sclerosis, a treatable disease. Clin Med. 2016;16(Suppl 6):s53-s59. doi:10.7861/clinmedicine.16-6-s53

3. Wallin MT, Culpepper WJ, Nichols E; GBD 2016 Multiple Sclerosis Collaborators. Global, regional, and national burden of multiple sclerosis 1990-2016: a systematic analysis for the Global Burden of Disease Study 2016. Lancet Neurol. 2019;18(3):269-285. doi:10.1016/S1474-4422(18)30443-5

4. Ahlgren C, Odén A, Lycke J. High nationwide prevalence of multiple sclerosis in Sweden. Mult Scler. 2011;17(8):901-908. doi:10.1177/ 1352458511403794

5. Bergamaschi R. Prognostic factors in multiple sclerosis. Int Rev Neurobiol. 2007;79:423-447.

6. McFarland HF, Martin R. Multiple sclerosis: a complicated picture of autoimmunity. Nat Immunol. 2007;8(9):913-919. doi:10.1038/ni1507

7. Pandit L, Murthy JM. Treatment of multiple sclerosis. Ann Indian Acad Neurol. 2015;50(Suppl 3):S65-S69. doi:10.4103/0972-2327.83094

8. Hartung DM, Bourdette DN, Ahmed SM, Whitham RH. The cost of multiple sclerosis drugs in the US and the pharmaceutical industry: too big to fail? Neurology. 2015;84(21):2185-2192. doi:10.1212/ WNL.0000000000001608

9. Arneth BM. Impact of B cells to the pathophysiology of multiple sclerosis. J Neuroinflammation. 2019;16(1):128. doi:10.1186/s12974019-1517-1

10. Kalincik T, Brown JWL, Robertson N, et al. Treatment effectiveness of alemtuzumab compared with natalizumab, fingolimod, and interferon beta in relapsing-remitting multiple sclerosis: a cohort study. Lancet Neurol. 2017;16(4):271-281. doi:10.1016/S1474-4422(17) 30007-8

11. Mancardi G, Sormani MP, Muraro PA, Boffa G, Saccardi R. Intense immunosuppression followed by autologous haematopoietic stem cell transplantation as a therapeutic strategy in aggressive forms of multiple sclerosis. Mult Scler. 2018;24(3):245-255. doi:10.1177/ 1352458517742532

12. Atkins HL, Bowman M, Allan D, et al. Immunoablation and autologous haemopoietic stem-cell transplantation for aggressive multiple sclerosis: a multicentre single-group Phase 2 trial. Lancet. 2016;388 (10044):576-585. doi:10.1016/S0140-6736(16)30169-6

13. Curro' D, Vuolo L, Gualandi F, et al. Low intensity lympho-ablative regimen followed by autologous hematopoietic stem cell transplantation in severe forms of multiple sclerosis: a MRI-based clinical study. Mult Scler. 2015;21(11):1423-1430. doi:10.1177/1352458514564484

14. Nash RA, Hutton GJ, Racke MK, et al. High-dose immunosuppressive therapy and autologous hematopoietic cell transplantation for relapsing-remitting multiple sclerosis (HALT-MS): a 3-year interim report. JAMA Neurol. 2015;72(2):159-169. doi:10.1001/jamaneurol.2014.3780

15. Sharrack B, Saccardi R, Alexander T, et al. Autologous haematopoietic stem cell transplantation and other cellular therapy in multiple sclerosis and immune-mediated neurological diseases: updated guidelines and recommendations from the EBMT Autoimmune Diseases Working Party (ADWP) and the Joint Accreditation Committee of EBMT and ISCT (JACIE). Bone Marrow Transplant. 2020;55 (2):283-306. doi:10.1038/s41409-019-0684-0

16. Cohen JA, Baldassari LE, Atkins HL, et al. Autologous hematopoietic cell transplantation for treatment-refractory relapsing multiple sclerosis: position statement from the American Society for Blood and Marrow Transplantation. Biol Blood Marrow Transplant. 2019;25(5):845-854. doi:10.1016/j.bbmt.2019.02.014

17. Bertolotto A, Martire S, Mirabile L, Capobianco M, De Gobbi M, Cilloni D. Autologous Hematopoietic Stem Cell Transplantation (AHSCT): standard of care for relapsing-remitting multiple sclerosis patients. Neurol Ther. 2020;9(2):197-203. doi:10.1007/s40120-02000200-9 
18. Sormani MP, Snowden JA; European Society for Blood and Marrow Transplantation (EBMT) Autoimmune Diseases Working Party (ADWP) and the Joint Accreditation Committee of the International Society for Cellular Therapy (ISCT) and EBMT (JACIE). Autologous haematopoietic stem cell transplantation and other cellular therapy in multiple sclerosis and immune-mediated neurological diseases: updated guidelines and recommendations from the EBMT Autoimmune Diseases Working Party (ADWP) and the Joint Accreditation Committee of EBMT and ISCT (JACIE). Bone Marrow Transplant. 2020;55(2):283-306.

19. Miller AE, Chitnis T, Cohen BA, et al. Autologous hematopoietic stem cell transplant in multiple sclerosis: recommendations of the National Multiple Sclerosis Society. JAMA Neurol. 2021;78 (2):241-246. doi:10.1001/jamaneurol.2020.4025

20. Passweg J, Baldomero H, Bader P, et al. Is the use of unrelated donor transplantation leveling off in Europe? The 2016 European Society for Blood and Marrow Transplant activity survey report. Bone Marrow Transplant. 2018;53:1139-1148. doi:10.1038/s41409-0180153-1

21. Passweg JR, Baldomero H, Basak GW, et al. The EBMT activity survey report 2017: a focus on allogeneic HCT for nonmalignant indications and on the use of non-HCT cell therapies. Bone Marrow Transplant. 2019;54(10):1575-1585. doi:10.1038/s41409-019-0465-9

22. Snowden JA, Badoglio M, Labopin M, et al. Evolution, trends, outcomes, and economics of hematopoietic stem cell transplantation in severe autoimmune diseases. Blood Adv. 2017;1:2742-2755. doi:10.1182/bloodadvances.2017010041

23. Fassas A, Anagnostopoulos A, Kazis A, et al. Peripheral blood stem cell transplantation in the treatment of progressive multiple sclerosis: first results of a pilot study. Bone Marrow Transplant. 1997;20:631-638. doi:10.1038/sj.bmt.1700944

24. Burt RK, Traynor AE, Cohen B, et al. T cell-depleted autologous hematopoietic stem cell transplantation for multiple sclerosis: report on the first three patients. Bone Marrow Transplant. 1998;21:537-541. doi:10.1038/sj.bmt.1701129

25. Zhukovsky C, Sandgren S, Silfverberg T, et al. Autologous haematopoietic stem cell transplantation compared with alemtuzumab for relapsing-remitting multiple sclerosis: an observational study. J Neurol Neurosurg Psychiatry. 2020;jnnp-2020-323992.

26. Boffa G, Lapucci C, Sbragia E, et al. Aggressive multiple sclerosis: a single-centre, real-world treatment experience with autologous haematopoietic stem cell transplantation and alemtuzumab. Eur J Neurol. 2020;27(10):2047-2055. doi:10.1111/ene.14324

27. Chen B, Zhou M, Ouyang J, et al. Long-term efficacy of autologous haematopoietic stem cell transplantation in multiple sclerosis at a single institution in China. Neurol Sci. 2012;33(4):881-886. doi:10.1007/s10072-011-0859-y

28. Mancardi GL, Sormani MP, Di Gioia M, et al. Autologous haematopoietic stem cell transplantation with an intermediate intensity conditioning regimen in multiple sclerosis: the Italian multi-centre experience. Mult Scler. 2012;18(6):835-842. doi:10.1177/ 1352458511429320

29. Muraro PA, Pasquini M, Atkins HL, et al. Long-term outcomes after autologous hematopoietic stem cell transplantation for multiple sclerosis. JAMA Neurol. 2017;74(4):459-469. doi:10.1001/ jamaneurol.2016.5867

30. Burt RK, Balabanov R, Burman J, et al. Effect of nonmyeloablative hematopoietic stem cell transplantation vs continued disease-modifying therapy on disease progression in patients with relapsing-remitting multiple sclerosis: a randomized clinical trial. JAMA. 2019;321(2):165-174. doi:10.1001/jama.2018.18743

31. Patti F. Optimizing the benefit of multiple sclerosis therapy: the importance of treatment adherence. Patient Prefer Adherence. 2010;4:1-9. doi:10.2147/PPA.S8230
32. Polman $\mathrm{CH}$, O'Connor PW, Havrdova E, et al. A randomized, placebo-controlled trial of natalizumab for relapsing multiple sclerosis. $N$ Engl J Med. 2006;354(9):899-910. doi:10.1056/ NEJMoa044397

33. Rudick RA, Stuart WH, Calabresi PA, et al. Natalizumab plus interferon beta-1a for relapsing multiple sclerosis. $N$ Engl $J$ Med. 2006;354 (9):911-923. doi:10.1056/NEJMoa044396

34. Bloomgren G, Richman S, Hotermans C, et al. Risk of natalizumab-associated progressive multifocal leukoencephalopathy. N Engl J Med. 2012;366(20):1870-1880. doi:10.1056/NEJMoa1107829

35. Kappos L, Radue EW, O’Connor P, et al. A placebo-controlled trial of oral fingolimod in relapsing multiple sclerosis. $N$ Engl $J$ Med. 2010;362(5):387-401.

36. Cohen JA, Barkhof F, Comi G, et al. Oral fingolimod or intramuscular interferon for relapsing multiple sclerosis. $N$ Engl $J$ Med. 2010;362(5):402-415. doi:10.1056/NEJMoa0907839

37. Sormani MP, Muraro PA, Schiavetti I, et al. Autologous hematopoietic stem cell transplantation in multiple sclerosis: a meta-analysis. Neurology. 2017;88(22):2115-2122. doi:10.1212/ WNL.0000000000003987

38. Tolf A, Fagius J, Carlson K, et al. Sustained remission in multiple sclerosis after hematopoietic stem cell transplantation. Acta Neurol Scand. 2019;140(5):320-327. doi:10.1111/ane.13147

39. Burman J, Iacobaeus E, Svenningsson A, et al. Autologous haematopoietic stem cell transplantation for aggressive multiple sclerosis: the Swedish experience. J Neurol Neurosurg Psychiatry. 2014;85 (10):1116-1121. doi:10.1136/jnnp-2013-307207

40. Mancardi GL, Sormani MP, Gualandi F, et al. Autologous hematopoietic stem cell transplantation in multiple sclerosis: a Phase II trial. Neurology. 2015;84(10):981-988. doi:10.1212/ WNL.0000000000001329

41. Burt RK, Balabanov R, Han X, et al. Association of nonmyeloablative hematopoietic stem cell transplantation with neurological disability in patients with relapsing-remitting multiple sclerosis. JAMA. 2015;313(3):275-284. doi:10.1001/jama.2014.17986

42. Moore JJ, Massey JC, Ford CD, et al. Prospective phase II clinical trial of autologous haematopoietic stem cell transplant for treatment refractory multiple sclerosis. J Neurol Neurosurg Psychiatry. 2019;90 (5):514-521. doi:10.1136/jnnp-2018-319446

43. Casanova B, Jarque I, Gascón F, et al. Autologous hematopoietic stem cell transplantation in relapsing-remitting multiple sclerosis: comparison with secondary progressive multiple sclerosis. Neurol Sci. 2017;38(7):1213-1221. doi:10.1007/s10072-017-2933-6

44. Muraro PA, Martin R, Mancardi GL, Nicholas R, Sormani MP, Saccardi R. Autologous haematopoietic stem cell transplantation for treatment of multiple sclerosis. Nat Rev Neurol. 2017;13(7):391-405. doi:10.1038/nrneurol.2017.81

45. Nash RA, Hutton GJ, Racke MK, et al. High-dose immunosuppressive therapy and autologous HCT for relapsing-remitting MS. Neurology. 2017;88(9):842-852. doi:10.1212/WNL.0000000000003660

46. Fassas A, Kimiskidis VK, Sakellari I, et al. Long-term results of stem cell transplantation for MS: a single-center experience. Neurology. 2011;76(12):1066-1070. doi:10.1212/WNL.0b013e318211c537

47. Coles AJ, Cohen JA, Fox EJ, et al. Alemtuzumab CARE-MS II 5-year follow-up: efficacy and safety findings. Neurology. 2017;89 (11):1117-1126. doi:10.1212/WNL.0000000000004354

48. Hauser SL, Bar-Or A, Comi G, et al. Ocrelizumab versus interferon beta-1a in relapsing multiple sclerosis. $N$ Engl J Med. 2017;376 (3):221-234. doi:10.1056/NEJMoa1601277

49. Das J, Sharrack B, Snowden JA. Autologous haematopoietic stem cell transplantation in multiple sclerosis: a review of current literature and future directions for transplant haematologists and oncologists. Curr Hematol Malig Rep. 2019;14(2):127-135. doi:10.1007/s11899019-00505-z 
50. Burt RK, Loh Y, Cohen B, et al. Autologous non-myeloablative haemopoietic stem cell transplantation in relapsing-remitting multiple sclerosis: a phase I/II study. Lancet Neurol. 2009;8(3):244-253. doi:10.1016/S1474-4422(09)70017-1

51. Saccardi R, Kozak T, Bocelli-Tyndall C, et al. Autologous stem cell transplantation for progressive multiple sclerosis: update of the European Group for Blood and Marrow Transplantation autoimmune diseases working party database. Mult Scler. 2006;12(6):814-823. doi:10.1177/1352458506071301

52. Sharrack B, Saccardi R, Alexander T, et al. Autologous hematopoietic stem cell transplantation with reduced-intensity conditioning in multiple sclerosis. Exp Hematol. 2012;40(11):892-898. doi:10.1016/ j.exphem.2012.07.003

53. Shevchenko JL, Kuznetsov AN, Ionova TI, et al. Long-term outcomes of autologous hematopoietic stem cell transplantation with reduced-intensity conditioning in multiple sclerosis: physician's and patient's perspectives. Ann Hematol. 2015;94(7):1149-1157. doi:10.1007/s00277-015-2337-8

54. Dunn-Pirio AM, Heyman BM, Kaufman DS, Kinkel RP. Outcomes and cost-effectiveness of autologous hematopoietic cell transplant for multiple sclerosis. Curr Treat Options Neurol. 2019;21(10):53. doi:10.1007/s11940-019-0588-8

55. Hamerschlak N, Rodrigues M, Moraes DA, et al. Brazilian experience with two conditioning regimens in patients with multiple sclerosis: BEAM/horse ATG and $\mathrm{CY} /$ rabbit ATG. Bone Marrow Transplant. 2010;45(2):239-248. doi:10.1038/bmt.2009.127

56. Snowden JA, Saccardi R, Allez M, et al. Haematopoietic SCT in severe autoimmune diseases: updated guidelines of the European Group for Blood and Marrow Transplantation. Bone Marrow Transplant. 2012;47(6):770-790. doi:10.1038/bmt.2011.185

57. Ni XS, Ouyang J, Zhu WH, Wang C, Chen B. Autologous hematopoietic stem cell transplantation for progressive multiple sclerosis: report of efficacy and safety at three yr of follow up in 21 patients. Clin Transplant. 2006;20(4):485-489. doi:10.1111/j.1399 0012.2006.00510.x

58. Bowen JD, Kraft GH, Wundes A, et al. Autologous hematopoietic cell transplantation following high-dose immunosuppressive therapy for advanced multiple sclerosis: long-term results. Bone Marrow Transplant. 2012;47(7):946-951. doi:10.1038/bmt.2011.208

59. Burman J, Fransson M, Tötterman TH, Fagius J, Mangsbo SM, Loskog AS. T-cell responses after haematopoietic stem cell transplantation for aggressive relapsing-remitting multiple sclerosis. Immunology. 2013;140(2):211-219. doi:10.1111/imm.12129

60. Darlington PJ, Touil T, Doucet JS, et al. Diminished Th17 (not Th1) responses underlie multiple sclerosis disease abrogation after hematopoietic stem cell transplantation. Ann Neurol. 2013;73(3):341-354. doi:10.1002/ana.23784

61. Karnell FG, Lin D, Motley S, et al. Reconstitution of immune cell populations in multiple sclerosis patients after autologous stem cell transplantation. Clin Exp Immunol. 2017;189(3):268-278. doi:10.1111/cei.12985

Biologics: Targets and Therapy

\section{Publish your work in this journal}

Biologics: Targets and Therapy is an international, peer-reviewed journal focusing on the patho-physiological rationale for and clinical application of Biologic agents in the management of autoimmune diseases, cancers or other pathologies where a molecular target can be identified. This journal is indexed on PubMed Central, CAS, EMBase,
62. Delemarre EM, van den Broek T, Mijnheer G, et al. Autologous stem cell transplantation aids autoimmune patients by functional renewal and TCR diversification of regulatory T cells. Blood. 2016;127 (1):91-101. doi:10.1182/blood-2015-06-649145

63. de Paula A, Sousa A, Malmegrim KC, et al. Autologous haematopoietic stem cell transplantation reduces abnormalities in the expression of immune genes in multiple sclerosis. Clin Sci (Lond). 2015;128(2):111-120. doi:10.1042/CS20140095

64. Keir ME, Butte MJ, Freeman GJ, Sharpe AH. PD-1 and its ligands in tolerance and immunity. Annu Rev Immunol. 2008;26:677-704. doi:10.1146/annurev.immunol.26.021607.090331

65. Arruda LC, Lorenzi JC, Sousa AP, et al. Autologous hematopoietic SCT normalizes miR-16, -155 and $-142-3 p$ expression in multiple sclerosis patients. Bone Marrow Transplant. 2015;50(3):380-389. doi: $10.1038 / \mathrm{bmt} .2014 .277$

66. Waschbisch A, Atiya M, Linker RA, Potapov S, Schwab S, Derfuss T. Glatiramer acetate treatment normalizes deregulated microRNA expression in relapsing remitting multiple sclerosis. PLoS One. 2011;6(9):e24604.

67. Keller A, Leidinger P, Steinmeyer F, et al. Comprehensive analysis of microRNA profiles in multiple sclerosis including next-generation sequencing. Mult Scler. 2014;20(3):295-303. doi:10.1177/ 1352458513496343

68. Bomprezzi R, Ringnér M, Kim S, et al. Gene expression profile in multiple sclerosis patients and healthy controls: identifying pathways relevant to disease. Hum Mol Genet. 2003;12(17):2191-2199. doi:10.1093/hmg/ddg221

69. Sharief MK, Douglas M, Noori M, Semra YK. The expression of pro- and anti-apoptosis Bcl-2 family proteins in lymphocytes from patients with multiple sclerosis. J Neuroimmunol. 2002;125 (1-2):155-162.

70. De Oliveira GL, Ferreira AF, Gasparotto EP, et al. Defective expression of apoptosis-related molecules in multiple sclerosis patients is normalized early after autologous haematopoietic stem cell transplantation. Clin Exp Immunol. 2017;187(3):383-398. doi: $10.1111 /$ cei. 12895

71. Gosselin D, Rivest S. Immune mechanisms underlying the beneficial effects of autologous hematopoietic stem cell transplantation in multiple sclerosis. Neurotherapeutics. 2011;8(4):643-649. doi:10.1007/ s13311-011-0062-0

72. Harris KM, Lim N, Lindau P, et al. Extensive intrathecal T cell renewal following hematopoietic transplantation for multiple sclerosis. JCI Insight. 2020;5(2):e127655. doi:10.1172/jci.insight.127655

73. Abrahamsson SV, Angelini DF, Dubinsky AN, et al. Nonmyeloablative autologous haematopoietic stem cell transplantation expands regulatory cells and depletes IL-17 producing mucosal-associated invariant $\mathrm{T}$ cells in multiple sclerosis. Brain. 2013;136(Pt 9):2888-2903. doi:10.1093/brain/awt182
Scopus and the Elsevier Bibliographic databases. The manuscript management system is completely online and includes a very quick and fair peer-review system, which is all easy to use. Visit http://www.dovepress.com/testimonials.php to read real quotes from published authors. 